\title{
Sinotubular Junction
}

National Cancer Institute

\section{Source}

National Cancer Institute. Sinotubular Junction. NCI Thesaurus. Code C127642.

The terminus of the aortic root; the point at which the aorta attains a tubular configuration. 